\title{
Concepção da célula de trabalho de equipamento de auxílio à colheita da cana-de-açúcar sob a perspectiva da ergonomia e da segurança do trabalho
}

\author{
Design of a sugar cane harvester workstation using ergonomics and safety concepts
}

\author{
Renato Pezzin Júnior $^{I^{*}}$ Roberto Funes Abrahão ${ }^{\mathrm{I}}$ Mauro José Andrade Tereso
}

RESUMO

O trabalho busca conceber, a partir da perspectiva da ergonomia e da segurança do trabalho, a célula de trabalho do equipamento de auxílio à colheita denominado UNIMAC CANA. No posto de trabalho, o conceito mecânico proposto utiliza operadores na transferência da cana da frente de corte até o mecanismo de limpeza, buscando preservar parte da mão-de-obra utilizada na colheita manual. Baseado nos conceitos da Ergonomia de Concepção, foi realizada uma análise da atividade futura dos operadores através da construção de cenários e uma busca por situações de referência para o projeto do posto de trabalho. Princípios da Antropometria, Biomecânica e da Segurança do Trabalho foram utilizados na sua análise e dimensionamento. Os resultados obtidos demonstram a eficácia da Ergonomia de Concepção enquanto metodologia projetual, aplicada ao desenvolvimento de projetos inovadores.

Palavras-chave: ergonomia de concepção, projeto mecânico, colhedora de cana-de-açúcar.

\section{ABSTRACT}

This research seeks to contribute, under an ergonomic and work safety perspective, to the design of a sugar cane harvester workstation. The mechanical conception uses human operators in the transfer of sugar cane from the feed unity to the cleaner unit, trying to preserve part of the human labor traditionally used in manual harvest. Using ergonomics concepts, it was done a future activity analysis and scenery building for the design of the work stations. Anthropometric, Biomecanic and Work Safety principles were used in the analysis and design of the equipment. The results show the efficiency of conception ergonomics as a design methodological tool when applied to new mechanical concepts.

Key words: conception ergonomics, mechanical design, sugar cane harvest.

\section{INTRODUÇÃO}

A cana de açúcar é um dos principais produtos agrícolas brasileiros e vem crescendo em produção e demanda a cada dia. Cerca de $60 \%$ da colheita é feita ainda de forma manual, pois a possibilidade de mecanização é limitada, de acordo com a tecnologia disponível, pela topografia do terreno. Sob a ótica da ergonomia e da segurança do trabalho, os problemas associados à colheita manual da cana-de-açúcar são bem conhecidos: risco elevado de acidentes, alto custo energético e condições ambientais severas (GONZAGA et al., 2005). Além desses fatores, há o aspecto ambiental - ecológico, já que a colheita manual exige a queima prévia da palha. Cerca de 20 a 48 horas antes da colheita, é realizada a queima do canavial, para reduzir a folhagem e diminuir o risco de acidente com animais peçonhentos. A partir daí, os trabalhadores cortam a cana com facões e vão fazendo feixes para a medição da produtividade. O pagamento é por produção. A operação do corte é dividida nas seguintes etapas: corte da base da cana, desponte da ponteira e amontoamento ou enfileiramento, para que, numa etapa posterior do processo, o produto seja carregado em caminhões e transportado para a usina.

As colhedoras mecânicas disponíveis atualmente apresentam uma produtividade aproximada de 700 toneladas por dia, o que equivale ao trabalho de 70 cortadores. Sua utilização prescinde

IFaculdade de Engenharia Agrícola, Universidade Estadual de Campinas (UNICAMP), Av. Cândido Rondon, 501, 13083-875, Campinas, SP, Brasil. E-mail: pezzin@sj.unisal.br. *Autor para correspondência. 
da queima prévia, o que torna a colheita mecânica mais sustentável do ponto de vista ecológico. Por outro lado, a mecanização total implica o desemprego de um grande número de trabalhadores.

A Faculdade de Engenharia Agrícola da UNICAMP aborda esse problema propondo um conceito inovador de colheita semi-mecanizada, através do projeto de uma máquina denominada UNIMAC CANA (BRAUNBECK \& OLIVEIRA, 2006), composta por uma frente de corte, uma célula de trabalho, uma unidade de limpeza e uma carreta de descarga vertical, como ilustra a figura 1.

O equipamento, inicialmente proposto pela equipe de projeto, preservava parte da mãode-obra da colheita, utilizando de oito a 12 pessoas nos postos de operação, com quatro linhas de corte. Posteriormente, por razões operacionais, o número de linhas de corte foi reduzido para duas e o número de operadores para quatro pessoas. A produtividade esperada é de 200 toneladas por dia. Ao contrário das colhedoras convencionais, o corte é feito com a cana inteira, e não picada, o que resulta em melhor aproveitamento da biomassa. O projeto prevê que a máquina tenha capacidade de operar em terrenos com declividade de até $50 \%$. Além disso, o custo esperado de aquisição é da ordem de $30 \%$ do valor de uma colhedora convencional. Seu funcionamento pode ser descrito da seguinte forma: um disco flutuante faz o corte basal da cana que é levada por um transportador rotativo até a célula de trabalho, onde o operador cata os colmos e os transfere para o despalhador de rolos. Nessa etapa, é feito o despalhe e o desponte da cana. Na sequência, o colmo inteiro é lançado até a carreta de descarga vertical.

Para integrar as questões relativas à ergonomia e segurança à concepção da célula de

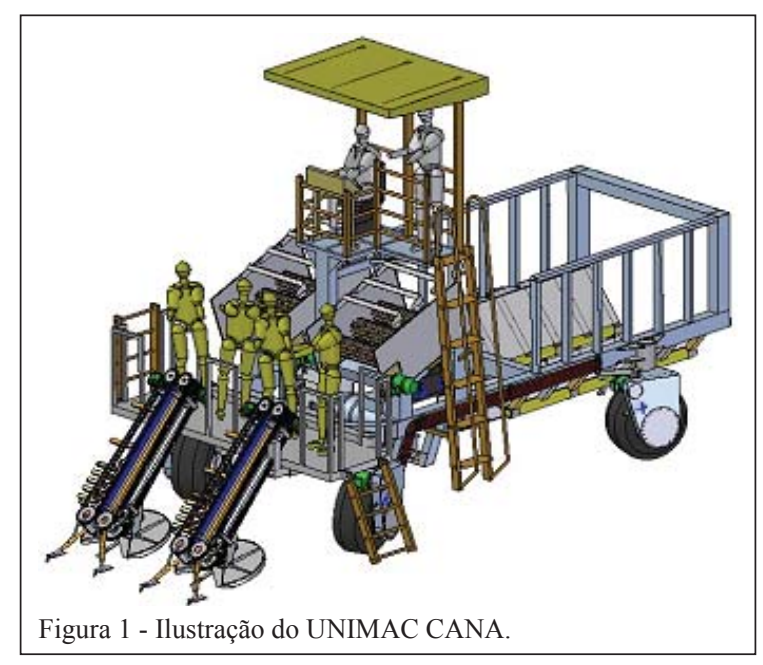

trabalho, destaca-se a metodologia projetual proposta por CLARK \& CORLETT (1984) - que utiliza dados antropométricos, biomecânicos e da análise das demandas da tarefa, em termos físicos e cognitivos além das normas regulamentadoras pertinentes.

Já a metodologia da análise da atividade futura, parte constituinte da ergonomia de concepção, utiliza situações de referência que delineiam um conjunto de ações típicas, conhecidas como situações de ação características. Isso permite a elaboração de diretrizes de projeto que se convertem em propostas concretas que, juntamente com as ações típicas, levam à construção de cenários da atividade futura. A partir disso, podem ser gerados prognósticos que levam a modificações projetuais, até que a equipe considere que os cenários construídos estejam suficientemente detalhados segundo os critérios adotados (DANIELLOU, 2007).

A ergonomia de concepção também permite que se examinem vários tipos de alternativas através de simulações de situações de trabalho de acordo com a tarefa a ser executada, em busca da melhor opção, tanto no que se refere, por exemplo, aos equipamentos de proteção individual (EPI) a serem utilizados, quanto às questões relativas à organização do trabalho.

Neste projeto, a análise não se configurou puramente como um trabalho de Ergonomia de Concepção (IIDA, 2005), já que teve início em um estágio avançado do projeto do equipamento, quando os principais elementos já estavam definidos e, em parte, construídos. Também não se configurou estritamente como Ergonomia de Correção, pois ainda havia margem de manobra para o dimensionamento favorável do posto de trabalho dos operadores.

Assim, este projeto teve por objetivo dimensionar a célula de trabalho do UNIMAC CANA, incorporando elementos das áreas da Ergonomia e da Segurança do Trabalho.

\section{MATERIAL E MÉTODOS}

A partir do modelo proposto por CLARK \& CORLET (1984), foi elaborada uma lista de verificação com o propósito de identificar os principais elementos ergonômicos e de segurança pertinentes ao projeto da célula de trabalho (Figura 2). Os fatores de risco envolvidos na tarefa foram previstos a partir de projeções de situações laborais, da análise de situações de referência e da consulta às normas do MINISTÉRIO DO TRABALHO E DO EMPREGO (2008): NR12 (máquinas e equipamentos), NR15 (atividades e operações insalubres), NR17 (ergonomia), 


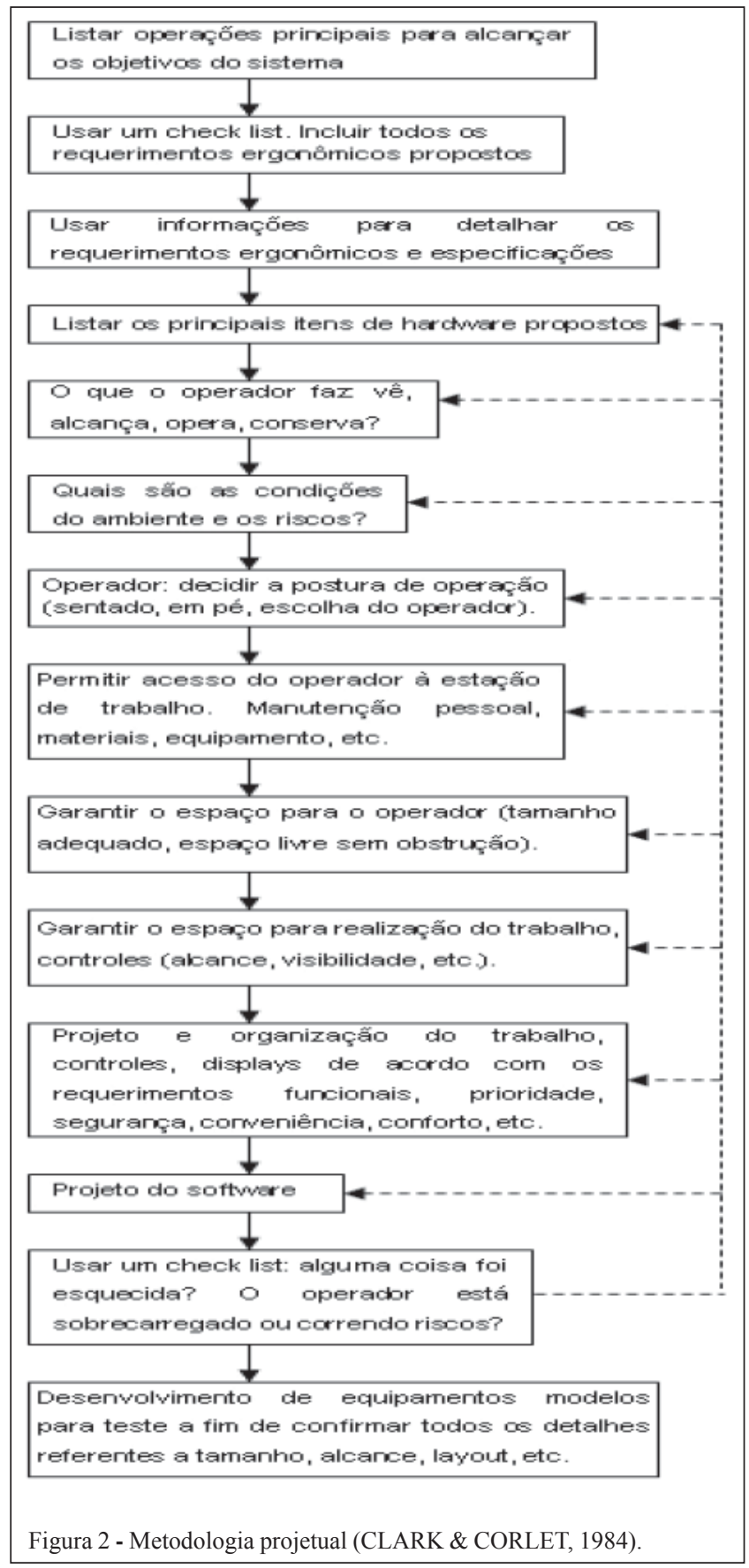

NR6 (EPI) e NR31 (trabalho na agricultura). Os riscos laborais foram classificados em físicos, químicos, biológicos, ergonômicos e riscos de acidentes, seguindo a metodologia proposta por GONÇALVES (1996).

Para o dimensionamento da célula de trabalho dos operadores, foram definidas as dimensões antropométricas relevantes ao projeto. Buscou-se otimizar o espaço de trabalho, favorecendo posturas corporais não penosas (GRANDJEAN, 2002). Neste projeto, foram utilizados os dados antropométricos da população brasileira publicados pelo INT (1995). Utilizaram-se as dimensões antropométricas que permitissem acomodar a maior faixa possível de operadores na célula de trabalho: os usuários maiores (percentil 95\% masculino) e os usuários menores (percentil 5\% feminino). As medidas maiores foram empregadas para se determinar as dimensões físicas da célula de trabalho, como o tamanho da plataforma 
(largura, comprimento), evitando assim riscos de acidentes por contato com partes móveis e espaço insuficiente para a locomoção dos usuários. Já as dimensões antropométricas do menor usuário foram utilizadas para definições de alcance e altura.

A estatura foi utilizada para determinar a altura mínima da célula de trabalho e a posição da plataforma em relação à cobertura e o solo. A altura do ombro foi utilizada para o posicionamento dos dispositivos da máquina. A distância vertical das pupilas ao solo foi utilizada para se determinar a linha de visão do trabalhador e evitar as possíveis obstruções visuais que pudessem prejudicar a execução da tarefa e a sua segurança. O alcance inferior máximo foi utilizado para determinar a altura mínima de alcance da cana pelo operador, sem que necessitasse se curvar para apanhá-la. A altura do cotovelo flexionado indicou a posição recomendada para a tarefa ser realizada. O comprimento interarticular ombro-cotovelo e comprimento do membro superior foram as medidas utilizadas para a determinação dos alcances dos operadores e, consequentemente, do posicionamento e dimensões dos dispositivos da célula de trabalho. A largura bideltoide foi utilizada para o dimensionamento da largura do posto de trabalho. $\mathrm{O}$ alcance frontal máximo e comprimento do antebraço-mão foram as medidas necessárias para se determinar o alcance máximo dos operadores. $\mathrm{O}$ comprimento máximo da mão foi utilizado para a construção de dispositivos de proteção para evitar que o operador tenha contato com partes móveis da máquina (Figura 3).

A análise biomecânica permitiu prever os gestos e posturas a serem adotados pelos operadores em função das características da tarefa, além do esforço físico envolvido em função dos parâmetros biomecânicos estimados. Com o intuito de verificar a viabilidade prática de execução da tarefa em função da velocidade de avanço da máquina e em função da inclinação da plataforma, foram realizadas buscas por situações de referência em outras áreas de atividade, como as linhas de produção da indústria e os trabalhos em plataformas móveis. As normas regulamentadoras e as situações de referência indicam a necessidade de barreiras de segurança, guarda-corpos, equipamentos de proteção individual, condições de acesso e saída do equipamento, rotas de fuga e faixas de visualização da tarefa.

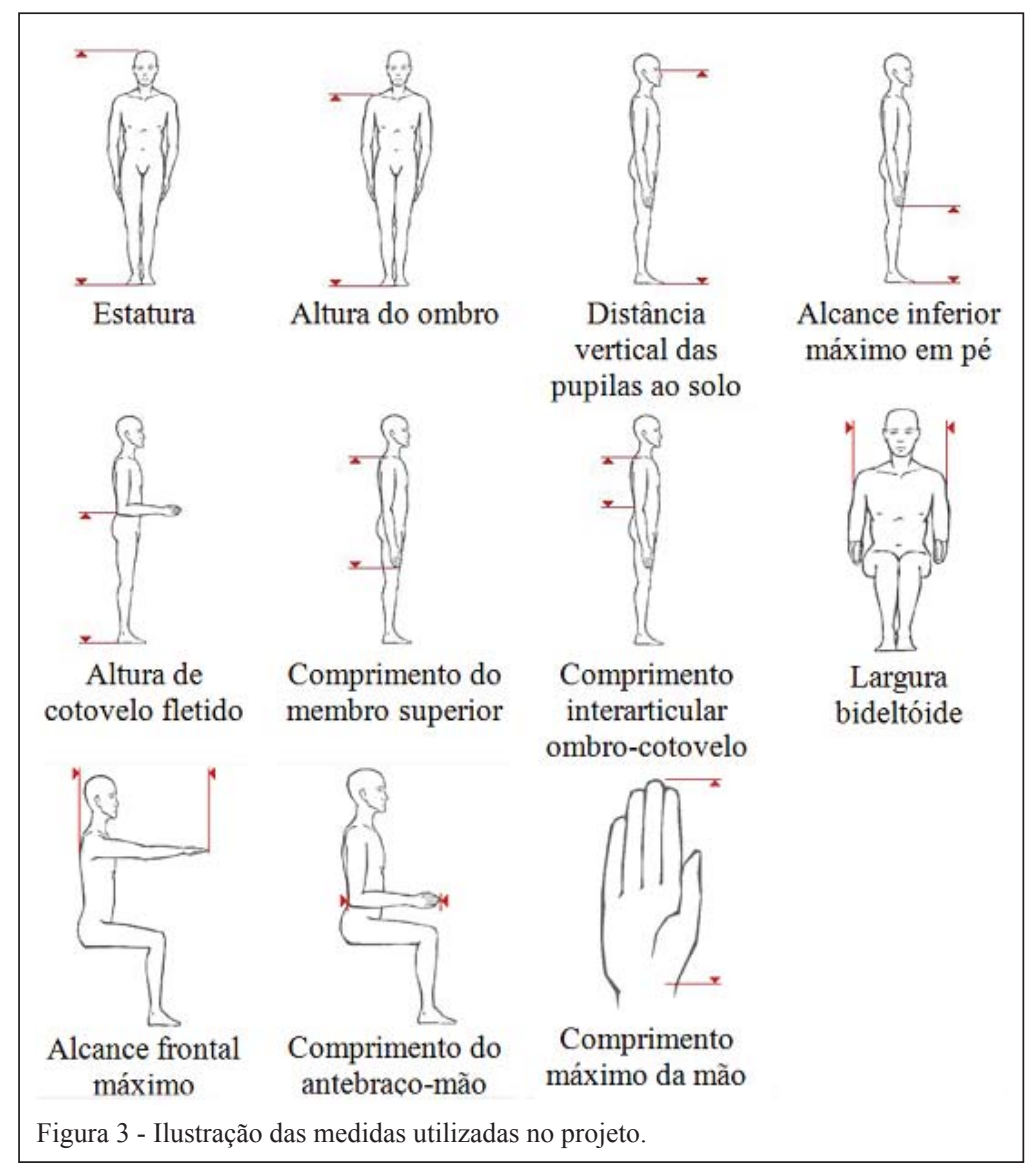

Ciência Rural, v.43, n.7, jul, 2013. 
Com a ajuda dessas situações de referência, foi possível definir as ações características para cada atividade. $\mathrm{O}$ diagnóstico das atividades ajudou a prever quais seriam os elementos com maior impacto sob uma perspectiva ergonômica. Para Ilustrar as situações previstas e ajudar na visualização da tarefa, foram criados os seguintes storyboards (Figura 4): a) Situação 1 - Colmo reto na posição longitudinal, chegando no ponto de captura a pelo menos $70 \mathrm{~cm}$ da base da plataforma. $\mathrm{O}$ operador deverá conseguir agarrar a cana e encaminhá-la para o despalhador, sem que exista a necessidade de flexão do tronco; b) Situação 2 - Colmo na posição vertical. O operador deverá girar o colmo para inseri-lo corretamente na unidade de limpeza; c) Situação 3 - Colmo torto. Chegará para o operador de maneira singular, com seu ponto de captura diferente do planejado. O colmo torto poderá enroscar-se na máquina fazendo com que o operador tenha que se deslocar para uma posição menos segura. Haverá uma dificuldade maior para o operador direcionar o colmo para o centro do despalhador; d) Situação 4 - Colmos sobrepostos/ velocidade acima do esperado. Como a frequencia de execução da tarefa é regida pela velocidade da máquina, se a máquina se deslocar com velocidade acima do esperado, poderá ocorrer a sobreposição de colmos. O operador se verá na posição de encaminhar uma carga mais volumosa e mais pesada para o centro do despalhador. Considerando-se as barreiras de proteção do despalhador, será muito difícil para o operador coordenar a inserção dos colmos neste contexto. Situação semelhante ocorrerá se o mecanismo de transporte capturar dois ou mais colmos simultaneamente; e) Situação 5 - Animais peçonhentos. Existe o risco dos colmos trazerem consigo alguns animais peçonhentos - como cobras,

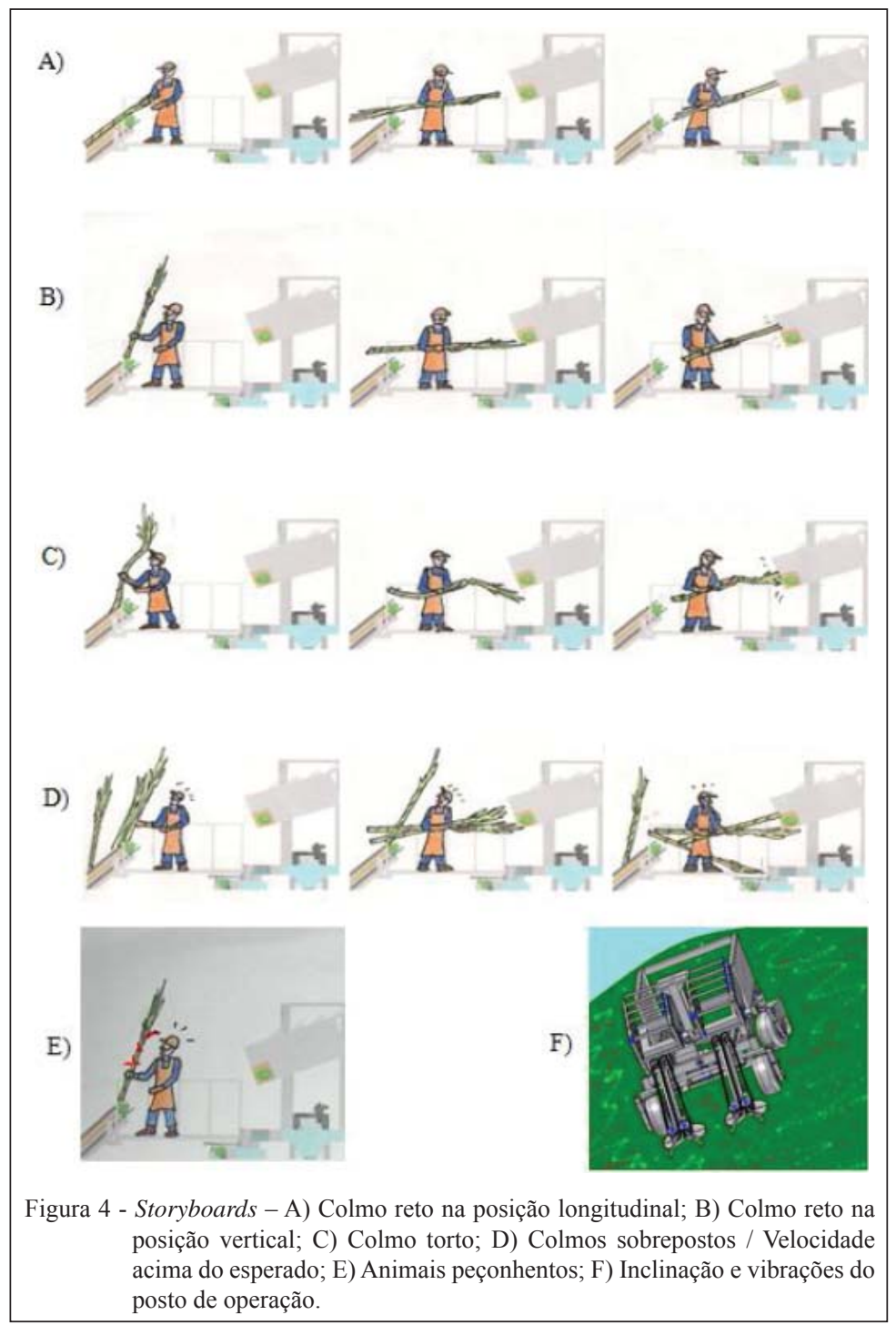

Ciência Rural, v.43, n.7, jul, 2013. 
aranhas e escorpiões. Essa situação tende a ocorrer porque não haverá queima prévia do canavial. É fundamental em uma situação como essa que o operador esteja adequadamente protegido e que haja rota de fuga; f) Situação 6 - Inclinação do Posto de Trabalho. Como está previsto para esta máquina operar em terrenos de alta declividade e acidentados, há o risco de desequilíbrio e queda dos operadores.

\section{RESULTADOS E DISCUSSÃO}

Os dados operacionais da máquina permitiram uma apreciação inicial da carga de trabalho dos operadores da célula. A velocidade de deslocamento da máquina oscilará entre 0,25 e $0,50 \mathrm{~km} \mathrm{~h}^{-1}$. Já a densidade prevista de colmos é de 10 a 35 colmos por metro linear. As estimativas adotam $1,5 \mathrm{~kg}$ como a massa média de um colmo. Sob essas condições, a frequência de captura poderá variar de 41,7 a 291,7 colmos por minuto, com fluxo mássico variando entre 62,5 a $437,0 \mathrm{~kg} \mathrm{~min}^{-1}$. A grande variabilidade da carga de trabalho em função dos parâmetros operacionais do equipamento ressalta o papel da organização do trabalho na definição da velocidade de deslocamento da máquina, de forma a atribuir uma carga de trabalho razoável aos operadores, equilibrada pelas frequências de pausas. Quanto menor a velocidade da máquina, menor a carga de trabalho imposta aos operadores na célula.

A partir dos dados antropométricos, da análise da atividade futura e das Normas Regulamentadoras, foram definidas as principais dimensões para o posto de trabalho, como altura da frente de alimentação e do despalhador com relação ao piso, a largura e o comprimento da célula de trabalho, bem como a definição dos dispositivos de segurança. Este dimensionamento permite que o trabalho na célula seja executado em condições biomecânicas menos desfavoráveis. Além disso, a célula projetada respeita as distâncias de segurança previstas pelas normas e deixa espaço para rotas de fuga. Em relação aos dispositivos de segurança, foram definidos o guarda-corpo e as proteções contra as partes móveis. A figura 5 sintetiza esses resultados.

Os métodos de análise da atividade futura e as Normas Regulamentadoras foram de fundamental importância para a recomendação de EPI para os trabalhadores da célula: a) Protetor facial - devido ao risco por impacto por partículas volantes e colmos; b) Luvas, macacão e botas - para proteção do corpo, devido ao risco de agentes cortantes e perfurantes; c) Dispositivo

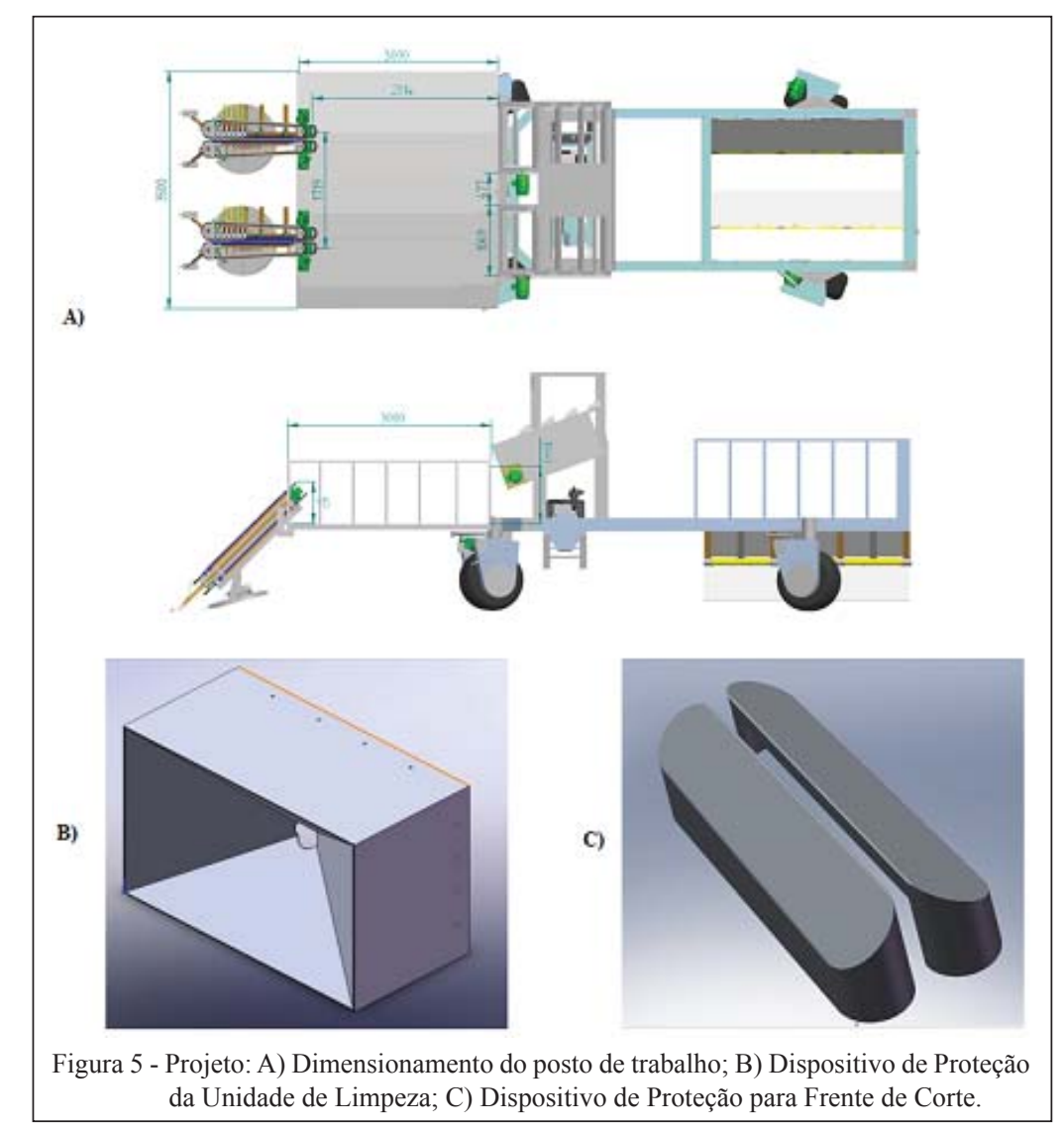

Ciência Rural, v.43, n.7, jul, 2013. 
trava-queda e cinturão - para proteção de quedas por diferença de nível e operações em movimento; d) Protetor auricular - para proteger o operador dos níveis de ruído provenientes das partes móveis e motores, caso sejam ultrapassados os $85 \mathrm{~dB}$ previstos pela NR15.

A contribuição ergonômica ao conceito proposto dependeu essencialmente dos estudos apontados pela metodologia projetual, como a busca por situações de referência, a análise da atividade futura e o levantamento das normatizações pertinentes ao desenvolvimento do projeto. Caso o dimensionamento da célula, sob a ótica da ergonomia e da segurança do trabalho, tivesse acontecido no início do ciclo de projeto do equipamento UNIMAC CANA, a contribuição poderia ter sido mais completa, inclusive com a possibilidade de interferência no layout desse equipamento.

\section{CONCLUSÃO}

A utilização dos dados antropométricos e biomecânicos da população brasileira e da metodologia proposta por Clark \& Corlett permitiu o redimensionamento da célula de trabalho da UNIMAC CANA sob a perspectiva da Ergonomia de Concepção e da Legislação sobre a Segurança do Trabalho. Um estudo experimental em condições reais de trabalho seria importante para corroborar as soluções propostas.

\section{REFERÊNCIAS}

GONÇALVES, E.A. Segurança e medicina do trabalho. São Paulo: LTr, 1996. 1072p.

GONZAGA, M. C. et al. O Uso de luvas de proteção no corte manual de cana-de-açúcar. Revista Brasileira de Saúde Ocupacional, São Paulo, v.30, n.111, p.35-40, 2005. Disponível em: $<$ http://www.fundacentro. gov.br/rbso/rbso_edicoes.asp? $\mathrm{SD}=\mathrm{RBSO} \& \mathrm{M}=98 / 0 \&$ Pagina $=3>$. Acesso em: 15 fev. 2008

BRAUNBECK, O.A.; OLIVEIRA, J.T.A. Colheita de canade-açúcar com auxílio mecânico. Engenharia Agrícola Jaboticabal, v.26, n.1, p.143-155, 2006. Disponível em: <http:// www.scielo.br/scielo.php? script $=$ sci arttext\&pid $=$ S010069162006000100032\&lng $=$ pt\&nrm $=\mathrm{iso}>$. Acesso em: 12 jan. 2008. doi: 10.1590/S0100-69162006000100032.

GRANDJEAN, E. Manual de ergonomia: adaptando o trabalho ao homem. Porto Alegre: Bookman, 2002. 339p.

IIDA, I. Ergonomia: projeto e produção. 2ed. São Paulo: Edgard Blucher, 2005. 614p.

CLARK, T.S.; CORLETT, E.N. The ergonomics of workspaces and machines: a design manual. London: Taylor \& Francis, 1984. 128p.

DANIELLOU, F. A ergonomia na condução de projetos de concepção de sistemas de trabalho. In: FALZON, P. Ergonomia. São Paulo: Edgard Blucher, 2007. Cap.21, 640p.

INT. Manual de aplicação dos dados antropométricos: ERGOKIT. Rio de Janeiro: Instituto Nacional de Tecnologia, 1995. 79p.

MINISTÉRIO DO TRABALHO E DO EMPREGO. Normas regulamentadoras. Disponível em: <http://www.mte.gov.br/ legislacao/normas regulamentadoras>. Acesso em: 01 fev. 2008. 